\title{
Further Investigation on Limb Dieback of Fig (Ficus carica) Caused by Neoscytalidium dimidiatum in California
}

\author{
Giorgio Gusella, ${ }^{1,2}$ David P. Morgan, ${ }^{2}$ and Themis J. Michailides ${ }^{2, \dagger}$ \\ ${ }^{1}$ Dipartimento di Agricoltura, Alimentazione e Ambiente, Sezione di Patologia Vegetale, University of Catania, Catania 95123, \\ Italy \\ ${ }^{2}$ Department of Plant Pathology, University of California-Davis, Kearney Agricultural Research and Extension Center, Parlier, \\ CA 93648, U.S.A.
}

\begin{abstract}
Fig limb dieback is a cosmopolitan disease caused by Neoscytalidium dimidiatum (Botryosphaeriaceae), characterized by branch and shoot cankers, discoloration of woody tissues, and dieback. The present study investigated the etiology of the disease in California that seems to have become prevalent among fig orchards in the last several years. During orchard surveys in Fresno, Kern, and Madera Counties over 3 years, we isolated consistently and evaluated the pathogenicity of $N$. dimidiatum under laboratory and field conditions. The effect of summer and winter pruning on the disease severity and the effects of different environmental and mechanical stresses, such as sunburn and wounding by mallets, were

demonstrated that $N$. dimidiatum induces cankers on fig, mainly on wounded shoots. Results from the remaining experiments revealed that summer infection leads to more severe canker lesions than those induced by winter infection and that stressed shoots are more susceptible to infection than nonstressed shoots. 'Brown Turkey', 'Conadria', and 'Calimyrna' cultivars (all nonpersistent figs, i.e., needing pollination for fruit development) were less susceptible than the more susceptible 'Kadota', 'Sierra', and 'Black Mission' (all persistent figs, i.e., not needing pollination for fruit development). Canker removal from the orchard seems to be a good agronomic practice to avoid the spread of disease.
\end{abstract} assayed. In addition, the susceptibility of six different cultivars and the effects of eradicating cankered shoots from the fig trees as a method to combat the spread of the disease were studied. Pathogenicity tests
Keywords: Botryosphaeriaceae, cankers, Ficus carica, fig, limb dieback, Neoscytalidium dimidiatum
Fig (Ficus carica L.) acreage in the United States in 2017 reached 6,700 bearing acres producing 31,200 tons of fig (www.nass.usda. gov). Although the world's top three producer countries are Turkey, Egypt, and Morocco, the United States is in the top 10 (www.fao.org), with the state of California ranking first in the nation, accounting for nearly $98 \%$ of all U.S. figs produced (www.agmrc. org). The commercial cultivation of fig is an important crop, providing economic income to many Mediterranean countries and to the California fig industry, with the latter supporting research to improve the quality of the product, postharvest advanced technologies, and marketing (Crisosto et al. 2017).

Many diseases are reported to affect figs in California and worldwide (Michailides 2003). Figs grown in California can suffer extensive losses due to fruit decay caused by fungi such as Fusarium moniliforme (endosepsis) (Michailides and Morgan 1998), Aspergillus niger (smut), Alternaria, and Ulocladium (Doster et al. 1996; Michailides 2003). In addition, canker diseases could represent a serious threat for fig growers, causing progressive yield losses over the years. In California, diseases caused by Botryosphaeriaceae spp. and Diaporthaceae spp. have been extensively investigated over the years (Chen et al. 2014a, b; Moral et al. 2019), revealing the presence of numerous taxonomic groups of species affecting different crops (Inderbitzin et al. 2010). These pathogens can induce severe symptoms, such as branch, shoot, and trunk cankers, and also blight fruits and leaves. Many reports of canker and dieback diseases on Ficus

${ }^{\dagger}$ Corresponding author: T. J. Michailides; tjmichailides@ucanr.edu

Funding: Funding was provided by the California Fig Institute (grant number CFI-2005), representing California fig growers and the California Fresh Fig Board.

The author(s) declare no conflict of interest.

Accepted for publication 5 August 2020.

(C) 2021 The American Phytopathological Society spp. have been published, showing Botryosphaeriaceae (Al-Bedak et al. 2018; El-Atta and Aref 2013; Mayorquin et al. 2012; Mohali et al. 2017) and Diaporthaceae (Hampson 1981; Lima et al. 2005; Rehab et al. 2014) involved in these complex diseases. In addition to other Ficus spp., the cultivated fig is also attacked by botryosphaeriaceous and diaporthaceous fungi worldwide (Aiello et al. 2020; Banihashemi and Javadi 2009; Çeliker and Michailides 2012; Javadi and Banihashemi 2005). Among members of the Botryosphaeriaceae family, Neoscytalidium dimidiatum was reported in several countries to cause cankers and dieback on different Ficus spp., including the common fig (Al-Bedak et al. 2018; Elshafie and Ba-Omar 2002; Giha 1975; Mirzaee et al. 2002; Ray et al. 2010). This species produces two different asexual states known as synanamorphs: the coelomycetous morph, producing pycnidia with conidia (Fusicoccum-like), and the hyphomycetous morph, producing powdery arthric chains of conidia (Scytalidium-like conidia or arthrospores) (Farr et al. 2005; Nattrass 1933; Sutton and Dyko 1989), which is the reason why it has been characterized by a restless taxonomic process, going through different names and descriptions (Torula dimidiata, Hendersonula toruloidea, Nattrassia mangiferae, Scytalidium dimidiatum, Scytalidium hyalinum, Fusicoccum dimidiatum, Neoscytalidium hyalinum). In 2006 Crous et al. (2006) established the new genus Neoscytalidium (Crous and Slippers). In California, this species was reported with the old name Hendersonula toruloidea on fig (Paxton et al. 1964; Warner 1952), walnut (Wilson 1949), citrus (Calavan and Wallace 1954), and recently as an emerging pathogen on citrus, grape, and almond (Mayorquin et al. 2016; Nouri et al. 2018; Rolshausen et al. 2013). Furthermore, symptoms of a canker disease on 'Kadota' figs in California were also reported in the early 1950s, associated with Phomopsis species (English 1951, 1952; Hansen 1949). However, the problem seemed to gradually fade away, probably because acreage of 'Kadota' has decreased significantly over the years. In the last several years, fig growers in California have noticed a large number of trees in many orchards losing large limbs because of severe dieback. On the basis of previous reports, and to elucidate the limb dieback disease of fig in California, we conducted several experiments with the following aims: to ascertain the incidence of the disease and the role of $N$. dimidiatum in the limb dieback etiology, to study the influence of environmental and 
agronomic factors in the disease etiology, and to evaluate the susceptibility of different fig cultivars to the disease in California.

\section{Materials and Methods}

Field survey and fungal isolations. A total of 16 fig orchards located in Fresno, Kern, and Madera Counties (central and southern San Joaquin Valley in California) were surveyed for 3 years (2005 to 2007), collecting every year about 10 to 15 branches and shoots showing symptoms of cankers and dieback from five different cultivars, including 'Black Mission', 'Calimyrna', 'Conadria', and also a Stanford caprifig (male tree) and another unknown caprifig cultivar. Symptomatic tissues were surface disinfected with household bleach at $10 \%(\mathrm{vol} / \mathrm{vol})$ in sterile water for $3 \mathrm{~min}$. Small pieces ( 3 to $5 \times 2$ to $5 \mathrm{~mm}$ ) from the margins of cankers were cut with a sterile scalpel and placed in Petri dishes containing $2 \%$ potato dextrose agar (PDA) acidified with lactic acid $(2.5 \mathrm{ml}$ of $25 \%$ [ $\mathrm{vol} / \mathrm{vol}$ ] per liter of medium; APDA) to minimize bacterial growth. Petri dishes were incubated at $25 \pm 3^{\circ} \mathrm{C}$ for 2 to 7 days, until fungal colonies were large enough to be examined. Occasionally tissue from stained wood segments distant from the canker margin, healthy-appearing wood away from the canker, infected lenticels or growth cracks, and tissue from insect borings were plated out. $N$. dimidiatum colonies were transferred to APDA dishes to obtain pure cultures, and single spore isolates were then stored in our collection. Recovered isolates used for further investigation are maintained in the culture collection of the Department of Plant Pathology at the University of California, Davis (Kearney Agricultural Research and Extension [KARE] Center in Parlier).

Effect of different temperatures on mycelial growth of $N$. dimidiatum. To determine the cardinal temperatures of growth, a 4.76-mm plug of a 3-day-old colony of the isolate of $N$. dimidiatum 2D3 was removed and transferred to the center of 90-mm Petri dishes of APDA and incubated at eight different temperatures, from 5 to $40^{\circ} \mathrm{C}$. Four Petri dishes were used for each temperature as replicates. The experiment was repeated once. After 3 days of incubation, the largest and smallest diameters of colonies were measured with a digital scale ruler. Mean data were converted to radial growth (in $\mathrm{mm}$ ). Data from two experiments were combined after checks for homogeneity of variances via $F$ test. A nonlinear adjustment of the data was applied via the generalized Analytis Beta model, as described by López-Moral et al. (2017), and the optimum growth temperature was calculated according to the formula provided by the same authors.

Pathogenicity tests on detached shoots. Preliminary pathogenicity tests were conducted on detached shoots collected from an experimental orchard at the KARE Center under laboratory conditions. Current season shoots ('Calimyrna'), 15 to $25 \mathrm{~cm}$ long, were surface sterilized for $4 \mathrm{~min}$ in a dilute mixture of bleach and alcohol $(160 \mathrm{ml}$ of $5.25 \% \mathrm{NaOHCl}$ bleach and $160 \mathrm{ml}$ of ethanol/10 liters of water) and allowed to air dry on plastic screens in plastic rectangular chambers of $30 \times 23 \times 10 \mathrm{~cm}$. A 7-mm in diameter plug from 14-day-old cultures of $N$. dimidiatum (isolates $3 \mathrm{C} 02,3 \mathrm{C} 07$ ) grown on APDA was used to inoculate each shoot. Wounds were made with a 7$\mathrm{mm}$ cork borer, and the mycelial plug was placed on each wound upside down and covered with semitransparent film (Parafilm "M") to prevent desiccation. Water was then added to the bottom of the plastic container to create a humid environment, and the containers were incubated at $30^{\circ} \mathrm{C}$. The experiment consisted of four treatments: wounded shoots noninoculated, nonwounded and inoculated, wounded and inoculated, and nonwounded and noninoculated. Ten shoots per treatment served as replicates. The experiment was repeated once with a slight modification, using 4-year-old shoots instead of current shoots. Presence of cankers (disease incidence) and length of cankers were recorded 40 days after the first experiment and 30 days after the repetition.

Pathogenicity test in the field. Based on the isolation results, pathogenicity tests in the field were conducted with $N$. dimidiatum (isolate 2D03) and Phomopsis sp. previously isolated from a symptomatic 'Calimyrna' fig limb in Madera County. These two species were inoculated onto 2-year-old shoots on 10 'Calimyrna' trees in the south row of an experimental orchard located at the KARE Center. A total of 15 shoots per treatment were used. Half of the shoots were tied to a string attached to a plastic bag filled with dried soil as a weight to bend the shoots at a $45^{\circ}$ angle and expose them more to direct sunlight to induce sunburn. The remaining shoots were left alone and were not exposed to direct sunlight because they were shaded by the foliage above them. A cork borer of 7-mm diameter was used to create a wound, and a mycelial plug of $7 \mathrm{~mm}$ of each fungus was used to inoculate each shoot. The wounds and the mycelial plugs were wrapped with semitransparent film to prevent desiccation. Control consisted of a sterile plug of PDA. The length of canker at either side of the inoculation was recorded after 1 year and 4 months. Reisolation from the margins of the cankers was done to fulfill Koch's postulates.

Effect of summer and winter pruning on infection development. To study the effect of summer and winter pruning on infection development, trees of the 'Calimyrna' experimental orchard at the KARE Center were pruned and inoculated in August and February in a spore suspension at a concentration of $1 \times 10^{5} \mathrm{spore} / \mathrm{ml}$ of $N$. dimidiatum isolate 3B02. Inoculations were made on both summer and winter pruning cuts at different times after pruning, at $0,1,2,3,4,5,6$, 7,14 , and 21 days after pruning, using 10 shoots per each treatment. These serial inoculations were performed to observe differences in the length of the lesions and then evaluate the period of susceptibility of pruning cuts. Pruned but noninoculated shoots served as controls. After the inoculum was sprayed on the pruning cut, the inoculated wounds were covered with semitransparent film to prevent desiccation. Length of the cankers was recorded twice: 1 and 2.5 years later for the summer pruning and 6 months and 2 years later for the winter pruning.

Effects of stress treatments on infection development. The effects of different environmental and agronomic stresses on the infection development were evaluated. Specifically, the effects of sunburn and mechanical injuries were studied. Eight treatments were conducted in this experiment: shoots wounded with mallet and inoculated; shoots wounded with mallets, sunburned, and then inoculated; shoots wounded only with mallets and noninoculated; shoots sunburned and then inoculated; shoots inoculated but nonwounded (control 1); shoots wounded but noninoculated (control 2); shoots wounded, inoculated, and painted with whitewash (SurroundR, NovaSource, Tessenderlo Kerley, Inc., Phoenix, AZ, U.S.A.); and shoots painted with whitewash and then inoculated. Large limbs (3 to 4 years old) of 15-year-old 'Calimyrna' trees located at the KARE Center were subjected to these stress treatments in August. To sunburn or heat the shoots above ambient conditions, portions of the shoots were wrapped with black plastic (Fig. 1E). To simulate wounding by mallets, shoots were wounded with the threaded end of a 7.94- $\times 304.8-\mathrm{mm}(5 / 16-$ $\times 12$-inch) carriage bolt. To cool them below ambient conditions, shoots were painted with a white tree trunk paint. In this experiment, 10 replicates were used for each treatment, for a total of 10 trees. Three weeks after the beginning of each treatment, the bark was removed with a 7-mm cork borer, and the shoots were inoculated with a $7-$ $\mathrm{mm}$ mycelial plug (isolate 3C02). Symptoms were recorded 2 and a half years after the inoculations.

Susceptibility of fig cultivars to the infection. To evaluate the susceptibility of various fig cultivars to the limb dieback, 'Brown Turkey', 'Black Mission', 'Calimyrna', 'Conadria', 'Kadota', and 'Sierra' were planted in an experimental orchard at the KARE Center and used for the experiment. A total of eight trees per cultivar were used, and two 1-year-old shoots per tree were inoculated with a 7-mm mycelial plug from a 14-day-old colony of the isolate 3C02 placed on wounds made with a 7-mm cork borer. Inoculations were performed in September, and results (length of cankers) were recorded twice, 2 months and 1 and a half years after the inoculations.

Cankers eradication and pathogen recovery. Existing cankers of different inoculation experiments were pruned $5.08 \mathrm{~cm}$ ( 2 inches) below the canker margin from half of the trees in the "effect of summer and winter pruning on infection development" experiment and from half of the trees in the "effects of stress treatments on infection 
development" experiment. Two years later the cankers from pruned and unpruned shoots were measured to see whether canker removal can contain pathogen movement in the shoots. Reisolations were made on acidified PDA from shoots subjected to this investigation to ascertain the possible recovery of $N$. dimidiatum.

Data analysis. Data of this study were analyzed in SAS (release 9.3; SAS Institute Inc.) and Statistix 10 (Analytical Software 2013). Data were tested for normality and homogeneity of variances, and then the analysis of variance was performed. Mean differences were compared with Fisher's least significance difference test at $P=0.05$.

\section{Results}

Field surveys, fungal isolations, symptoms, and signs of the disease. Results of the isolations from all 16 orchards surveyed in 3 years consistently showed the presence of $N$. dimidiatum, in both symptomatic and asymptomatic samples. Close examination of collected samples from trees with limb dieback revealed that the pathogen produced both arthrospores and pycnidia in woody tissues. Arthrospores are loose and develop in the space between the bark and the woody tissues from mycelia of the fungus that break into short pieces (Fig. 1D). Pycnidia were found embedded in the bark (Fig. 1C) and in general produced light-colored, unicellular pycnidiospores. The second most common fungus isolated from these surveys was Phomopsis spp., although its incidence seemed to decrease during this study. Phomopsis spp. incidence was surprisingly high $(100 \%)$ in the second year of survey in one orchard of cultivar 'Black Mission' (Table 1). Symptoms observed in the field included internal wood discoloration, branch canker and dieback, signs (pycnidia) of the pathogen in the bark, and arthrospores under the bark (Fig. 1A to $1 \mathrm{D})$. The following isolates of $N$. dimidiatum were used in this study: 2D3/2D03, 3C2/3C02, 3C7/3C07, and 3B02. Because of the uniformity and similar growth characteristics of these isolates, three random isolates, 2D3, 3C2, and 3C7, were molecularly identified on the basis of six loci in a study by Inderbitzin et al. (2010).

Effect of different temperatures on $N$. dimidiatum mycelial growth. After 3 days of incubation, no mycelial growth was observed at 5 and $10^{\circ} \mathrm{C}$. Mycelial growth was observed at all other temperatures, showing different mean values: $7.0 \mathrm{~mm}$ at $15^{\circ} \mathrm{C}, 11.1 \mathrm{~mm}$ at $20^{\circ} \mathrm{C}$, $36.3 \mathrm{~mm}$ at $25^{\circ} \mathrm{C}, 39.6 \mathrm{~mm}$ at $30^{\circ} \mathrm{C}, 38.0 \mathrm{~mm}$ at $35^{\circ} \mathrm{C}$, and $3.5 \mathrm{~mm}$ at $40^{\circ} \mathrm{C}$. Optimum growth occurred at $31.5^{\circ} \mathrm{C}$ (Fig. 2).

Pathogenicity tests on detached shoots. Pathogenicity tests conducted under laboratory conditions on detached current shoots, and

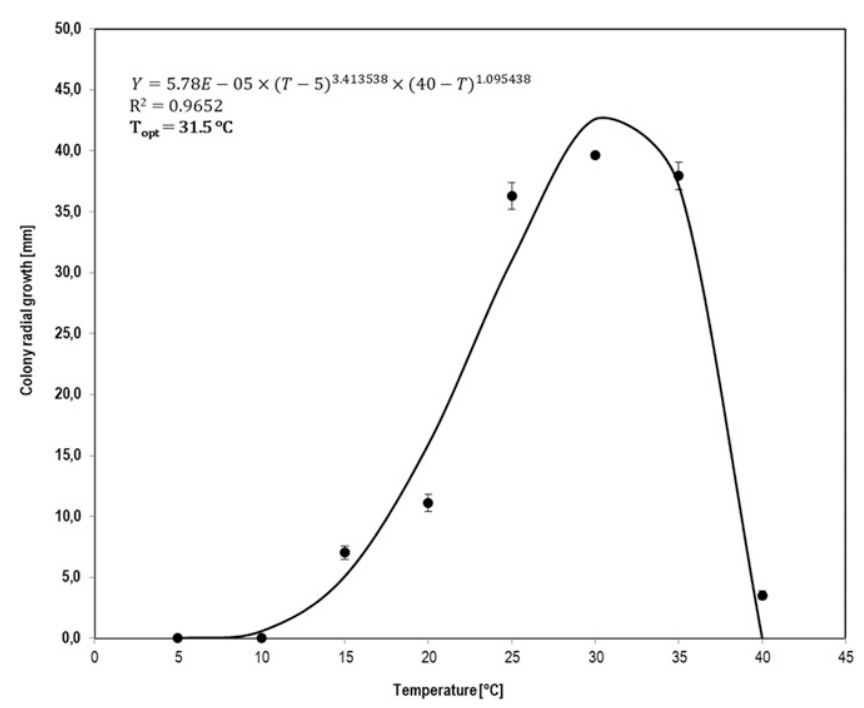

Fig. 1. Effect of temperature on mycelial growth of isolate D3 of Neoscytalidium dimidiatum. The averages of radial growth and temperature were adjusted to a nonlinear regression curve via the Analytis Beta model. $Y$ represents standardized radial growth. Data points are the means and vertical bars are the standard error of the means. 4-year-old detached shoots in experiment 2 , showed that $N$. dimidiatum causes canker on fig tissues. Specifically, in experiment 1 , three statistically different groups emerged from the analysis. Results with isolate $3 \mathrm{C} 7$ on wounded shoots are significantly different from those of all other treatments, showing the largest cankers. Inoculations with isolate $3 \mathrm{C} 2$ on wounded and unwounded shoots, and $3 \mathrm{C} 7$ on unwounded shoots, did not reveal statistically significant differences, showing an intermediate level of canker length. However, treatments with wounded and unwounded shoots not inoculated did not produce lesions, showing a separate statistical group. In both experiments the highest incidence $(100 \%)$ was recorded on wounded shoots inoculated with either isolate. In experiment 2, treatment with isolate $3 \mathrm{C} 7$ on wounded shoots produced the longest cankers, as it did in experiment 1 , followed by treatment with isolate $3 \mathrm{C} 2$ on wounded shoots, and the shortest lesions with the same isolate on unwounded shoots. Interestingly, isolate $3 \mathrm{C} 7$ inoculated on unwounded shoots did not produce lesions this time, and the incidence of infection was $0 \%$. In experiment 2 , the isolates induced smaller lesions than those in experiment 1 (Fig. 3). Arthrospores were abundant under the bark on these shoots, as were pycnidia with mature pycnidiospores.

Pathogenicity test in the field. Pathogenicity tests in the field conducted on 2-year-old shoots with $N$. dimidiatum (2D03) and an isolate of Phomopsis sp. revealed significant differences between the two species. $N$. dimidiatum induced lesions of $24.8 \mathrm{~mm}$ (no sunburn) and $19 \mathrm{~mm}$ (sunburn), but Phomopsis sp. did not induce any lesions significantly larger than the discoloration that resulted from the control (11.9 mm vs $10.9 \mathrm{~mm}$ ) (Table 2). This test in the field was performed also to determine effects of sunburn on the shoots inoculated with $N$. dimidiatum. In this experiment, there were no significant differences between the two treatments. Because maximum air temperature reached $32.2^{\circ} \mathrm{C}$ on only 4 days during the shoot inoculation experiment, the heat stress may not have been sufficient to show an effect (Table 2). However, because we observed that cankers were often associated with sunburned tissues, the hypothesis that sunburn affects Neoscytalidium canker was investigated separately in another experiment.

Effect of summer and winter pruning on infection development. Results from summer and winter pruning inoculations revealed significant differences between the two seasonal treatments. Cankers from summer pruning were significantly longer than those that occurred after winter pruning. Lesions were measured twice, at two different times, and in both cases significant differences were confirmed. In both evaluations the average length of summer lesions was $28.5 \mathrm{~cm}$, compared with $9 \mathrm{~cm}$ for the winter treatment. Very small lesions in the last treatments (21 days after pruning) were observed from the serial inoculation time after pruning, suggesting that pruning cuts become less susceptible after 3 weeks (data not shown).

Effects of stress treatments on infection development. This experiment was performed to see whether environmental or agronomic stresses could affect infection establishment and development. Limbs wounded with mallets and also sunburned had the largest cankers among all the treatments. Intermediate length of cankers was recorded for limbs only wounded with mallets or only sunburned, followed by limbs only wounded with mallets or only sunburned without fungal inoculation. No significant differences were recorded between the cankers on whitewashed limbs before and after inoculation and the nonwounded but inoculated control (Fig. 4).

Susceptibility of fig cultivars to the infection. The first symptom evaluation, conducted 2 months after the inoculation of the six fig cultivars, revealed two statistically different groups, with cultivars 'Sierra', Kadota', and 'Black Mission' being more susceptible than cultivars 'Brown Turkey', 'Conadria', and 'Calimyrna'. The second evaluation, performed a year and a half later, confirmed the results of the first evaluation, with the exception of cultivar 'Black Mission', which showed moderate susceptibility between the less susceptible 'Brown Turkey', 'Conadria', and 'Calimyrna' and the more susceptible 'Kadota' and 'Sierra' (Fig. 5).

Canker eradication and pathogen recovery. Pruning the shoots $5.08 \mathrm{~cm}$ below the obvious external margins of cankers effectively contained pathogen movement within the shoots. Isolations from 
the cut surface of pruned shoots from trees in both experimental orchards at the KARE Center produced no $N$. dimidiatum. Otherwise, the fig canker pathogen was consistently recovered from the margins of cankers in unpruned shoots that remained on the trees in this orchard (frequency average $=43 \%$ ).

\section{Discussion}

The present study investigated the etiology and epidemiology of fig limb dieback in California. Results from our surveys conducted in the main fig production counties of California reveal that the two most common species isolated from cankers of symptomatic branches and shoots were $N$. dimidiatum and Phomopsis spp. Phomopsis has been reported in other countries as an important fig canker pathogen. In Iran, its association with fig canker has been known for $>25$ years (Banihashemi, unpublished data). In California, Phomopsis cinerascens was reported in 1936 as an epidemic pathogen on the cultivar 'Kadota' (Ferguson et al. 1990). Phomopsis canker can be found in all commercial fig cultivars, but it is most devastating in 'Kadota' (Obenauf et. al. 1978). However, pathogenicity tests conducted in this study using both $N$. dimidiatum and Phomopsis spp. revealed that $N$. dimidiatum induced lesions, unlike Phomopsis. 'Kadota' probably was susceptible to Phomopsis infection during those years, and its progressive displacement with other cultivars, perhaps less susceptible, led to a decrease in the incidence of this pathogen over the years. When the surveys of orchards with putative canker diseases were performed, no commercial orchards of 'Kadota' were located in counties of the central San Joaquin Valley in California. The 3-year surveys of other fig cultivars showed high levels of both $N$. dimidiatum and Phomopsis spp. only in the first year, an indication that these pathogens could co-occur in the same canker tissues. However, in survey years 2 and 3, with the exception of one 'Black Mission' orchard where all samples produced Phomopsis spp., Phomopsis spp. were not isolated or were isolated at low levels in a few orchards (Table 1). Obviously, the incidence of Phomopsis spp. was reduced in years 2 and 3 from surveyed symptomatic tissues. In contrast, the incidence of $N$. dimidiatum was high in most samples during the 3-year survey. However, recent isolations have shown the presence of Phomopsis spp. associated with symptomatic samples, although at low percentage compared with Neoscytalidium frequency. Therefore, we can affirm that Phomopsis spp. is in somehow associated with the disease, but additional investigations are needed to confirm the interactions between these two species and disease development.

$N$. dimidiatum has been reported worldwide, causing diseases on many other important crops (Derviş et al. 2019; Polizzi et al. 2009; Rolshausen et al. 2013; Türkölmez et al. 2019), and in the study of Marques et al. (2013) it was considered the most aggressive of all Botryosphaeriaceae. A recent study conducted in California on almond branch and trunk cankers showed a high incidence of $N$. dimidiatum and confirms that this disease appeared to be widespread, suggesting a recent increase of this pathogen and the diseases it causes (Nouri et al. 2018). In California, the presence of different susceptible crops in contiguous areas allows an easy flow of inoculum (arthrospores) between tree species (Moral et al. 2019). Our optimum growth temperature results accord with those of Nouri et al. (2018), showing an optimum temperature of $31.5^{\circ} \mathrm{C}$. In this study we found a significant difference in lesion length between trees pruned in summer and those pruned in winter. Lesions from summer pruning were always significantly longer than those on winter-pruned trees. Also, winter pruning is less problematic than summer pruning, when more severe infections and higher inoculum levels can occur. These results demonstrate that summer temperatures are an important factor for the development of infection by $N$. dimidiatum, as stated by Hassan et al. (2011) and Sadowsky et al. (2007). In fact, both reports showed the effect of heat stress treatments as a predisposing factor to $N$. dimidiatum infection. In Israel, severe symptoms on grapefruits appeared after extremely hot and dry weather events for several consecutive days (Oren et al. 2001). In Oman, infection on Albizia lebbeck occurred in the summer of 1998 when the average temperature was $40^{\circ} \mathrm{C}$ (Elshafie and Ba-Omar 2002), as was observed in Iraq on different hosts (Hassan et al. 2009). Our results accord with previous research of English et al. (1975), who described the canker pathogen H. toruloidea in California as extremely temperature sensitive, able to cause appreciable infection only in summer. However, a recent study conducted in California on almond showed that $N$. dimidiatum isolates infected almonds regardless of the month of inoculation,

Table 1. Incidence of fungal species emerging from 3 years of surveys in Fresno, Madera, and Kern counties

\begin{tabular}{|c|c|c|c|c|c|}
\hline \multirow[b]{2}{*}{ Cultivar } & \multirow[b]{2}{*}{ Month } & \multicolumn{3}{|c|}{ Incidence (\%) } & \multirow[b]{2}{*}{ Year } \\
\hline & & Neoscytalidium dimidiatum & Phomopsis sp. & Botryosphaeriaceae sp. & \\
\hline Black Mission & May & 26.4 & 66.4 & 1.0 & 1 \\
\hline Calimyrna & May & 78.3 & 13.3 & & 1 \\
\hline Conadria & June & 82.2 & 7.8 & 7.8 & 1 \\
\hline Calimyrna & June & 65.5 & 32.2 & 3.3 & 1 \\
\hline Black Mission & June & 11.3 & 55.5 & 1.7 & 1 \\
\hline Black Mission & June & 6.7 & 93.3 & & 1 \\
\hline Calimyrna & May & 75 & 17 & & 2 \\
\hline Black Mission & May & 59 & 0 & & 2 \\
\hline Black Mission & May & 8 & 100 & & 2 \\
\hline Conadria & May & 86 & 0 & & 2 \\
\hline Caprifig & May & 85 & 0 & & 2 \\
\hline Conadria & May & 99 & 0 & & 2 \\
\hline Black Mission & May & 97 & 17 & & 2 \\
\hline Black Mission $^{\mathrm{w}}$ & May & 90 & 0 & & 2 \\
\hline Black Mission $^{\mathrm{x}}$ & May & 100 & 0 & & 2 \\
\hline Stanford caprifig & May & 90 & 3 & & 2 \\
\hline Calimyrna & May & 100 & 0 & & 2 \\
\hline Calimyrna & May & 85 & 10 & & 2 \\
\hline Calimyrna & May & 100 & 0 & & 2 \\
\hline Calimyrna & May & 32 & 39 & & 3 \\
\hline Black Mission & June & $84^{y}$ & 0 & & $\begin{array}{l}5 \\
3\end{array}$ \\
\hline Black Mission & November & $100^{\mathrm{z}}$ & 0 & & 3 \\
\hline
\end{tabular}

\footnotetext{
w Isolations from infected lenticels or growth cracks.

$\mathrm{x}$ Isolations from tunnels of boring insects.

y $N$. dimidiatum was isolated from $68 \%$ of the dark brown staining of the woody tissues in advance of the cankers.

$\mathrm{z} N$. dimidiatum was also isolated from $15 \%$ of symptomless shoots.
} 


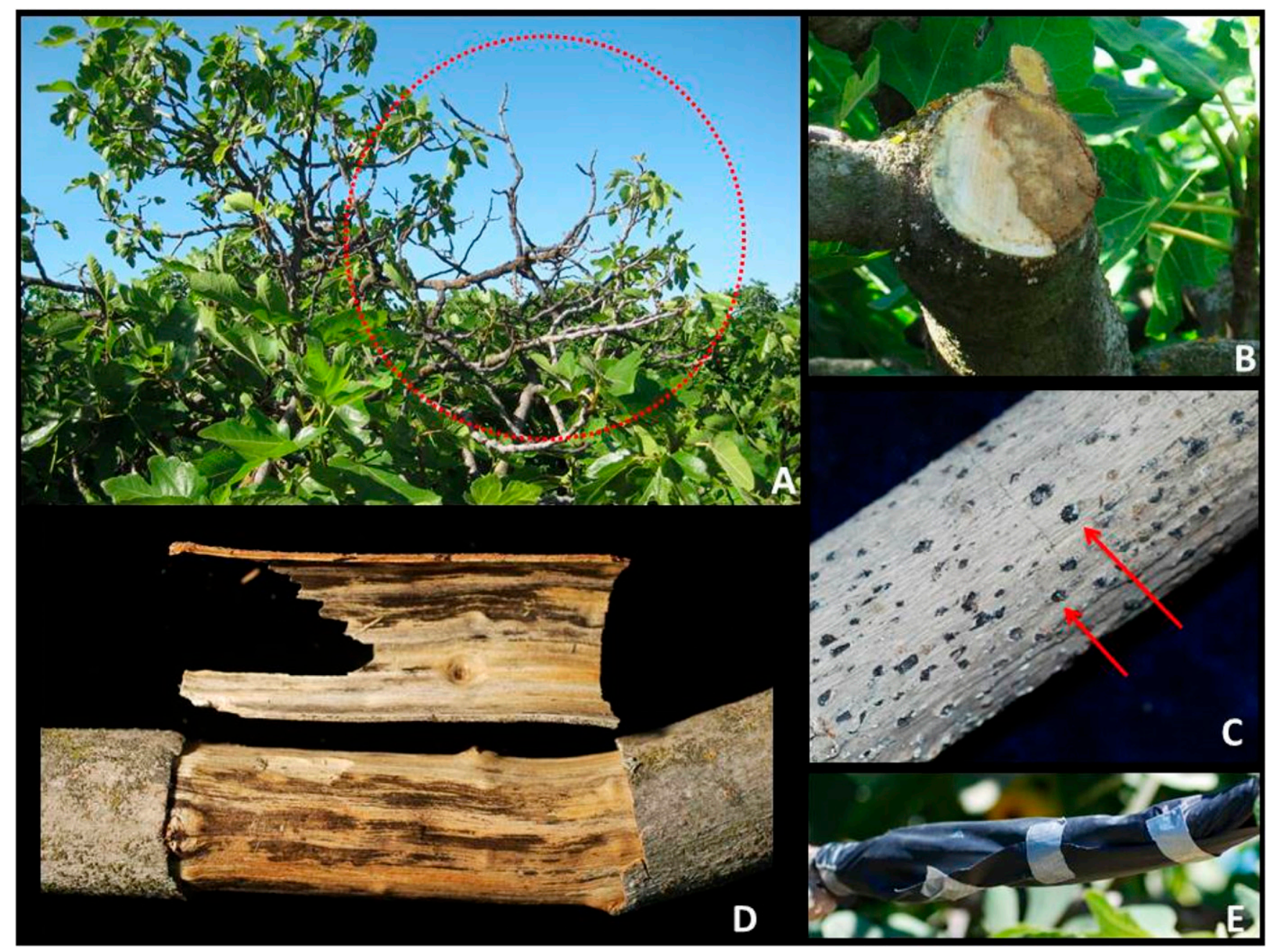

Fig. 2. Symptoms and signs of Neoscytalidium dimidiatum on fig. A, Limb dieback of cultivar 'Black Mission' in the field. B, Internal wood discoloration of cultivar 'Black Mission'. C, Pycnidia observed on fig shoot. D, Arthrospores developed under the bark. E, Shoot wrapped with black plastic to create the sunburn treatment.

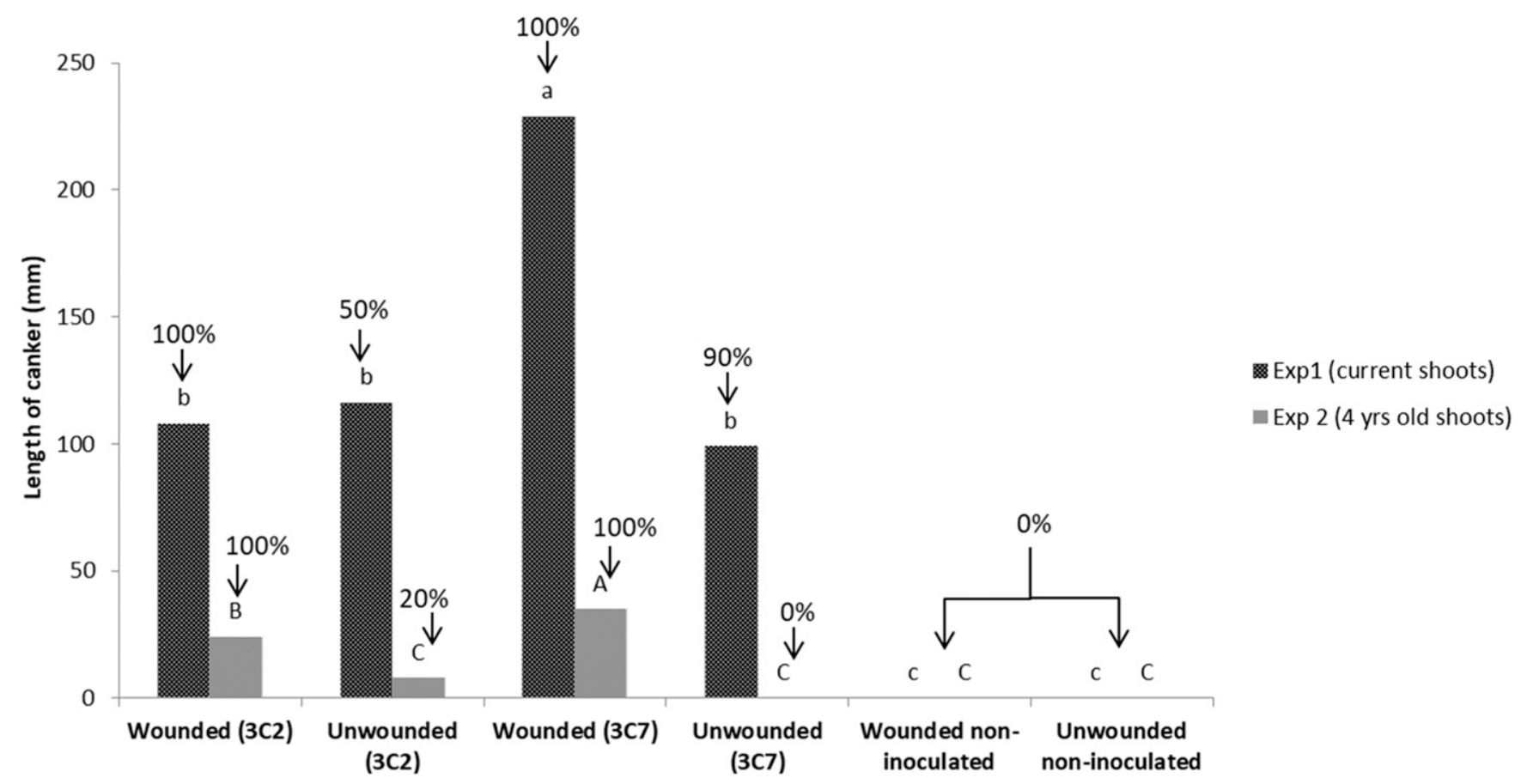

Fig. 3. Pathogenicity of Neoscytalidium dimidiatum on detached fig shoots. Average lesion length resulting from inoculation with a mycelium plug of $N$. dimidiatum onto current and 4 -year-old shoots. Percentages above the columns indicate the incidence of infection. Letters above the columns indicate treatments significantly different $(P<0.05)$. Letters refer to the specific experiment. 
although the authors affirmed that the winter of 2015 was particularly dry and warm (Nouri et al. 2018). Many authors refer to $N$. dimidiatum as a weak or opportunistic pathogen, invading tissues through wounds and openings, especially when the host is stressed. Schoeneweiss (1975) suggested that stress plays a key role, exerting its most pronounced effect by predisposing plants to facultative parasites, especially weak or nonaggressive pathogens. In this study, experiments conducted with different stress treatments demonstrated that the combination of mechanical injuries (mallet) and sunburn led to the longest cankers, followed by lesions derived from inoculations on wounded shoots (mallet) or only sunburned shoots. In this experiment, and in the pathogenicity tests on 4-year-old detached shoots, wounds seemed to be necessary to initiate the infection process. However, in pathogenicity tests on current shoots, the infection occurred also on unwounded ones, probably because the tissues were not lignified enough and the pathogen was able to penetrate without a preexisting wound. Similarly, in a study conducted on a dragon fruit canker disease caused by $N$. dimidiatum, Fullerton et al. (2018) concluded that the tissues most susceptible to infection were the tips of rapidly growing cladodes. Mature cladodes were highly resistant to infection. Davison (1972) showed that $H$. toruloidea can infect an unwounded tree at the ideal temperature of $25^{\circ} \mathrm{C}$, but wounding resulted in the higher disease incidence, supporting our results by suggesting that injuries such as sunburn, pruning wounds, and other mechanical injuries (i.e., mallet) are crucial in the infection process, as was also shown by other authors (Calavan and Wallace 1954; Nouri et al. 2018; Oren et al. 2001). Our results also showed that pruning wounds are susceptible to infection for $\geq 3$ weeks. The same experiment revealed that shoots treated with whitewash and inoculated did not produce lesions. Treatments with whitewash seem to be effective at both protecting trees from sunburn, thus

Table 2. Pathogenicity test in the field

\begin{tabular}{llc}
\hline Treatment & \multicolumn{1}{c}{ Species } & Canker length $(\mathbf{m m})$ \\
\hline Sunburn & Neoscytalidium dimidiatum & $19.0 \mathrm{a}^{\mathrm{z}}$ \\
Non-sunburn & N. dimidiatum & $24.8 \mathrm{a}$ \\
& Phomopsis sp. & $11.9 \mathrm{~b}$ \\
& Control & $10.9 \mathrm{~b}$ \\
\hline
\end{tabular}

${ }^{\mathrm{z}}$ Average lesion length $(\mathrm{mm})$. Letters indicate treatments that were significantly different $(P<0.05)$. preventing development of cracks and other wounds on shoots, and suppressing infection by the pathogen and canker formation.

In this investigation, six commercial fig cultivars were evaluated for their susceptibility to canker formation by $N$. dimidiatum. Among these cultivars, 'Brown Turkey', 'Conadria', and 'Calimyrna' (nonpersistent figs, i.e., needing pollination to keep the fruit) are less susceptible than cultivars 'Kadota' and 'Sierra', which were more susceptible, with the cultivar 'Black Mission' showing moderately susceptibility. Interestingly, these last three cultivars are persistent (i.e., they do not need pollination for fruit to develop). At the end of all experiments, we ascertained that pruning $5 \mathrm{~cm}$ below the canker could successfully remove the pathogen from the infected shoots. The pathogen was never recovered from shoots that were pruned $5 \mathrm{~cm}$ below the canker, an indication that the pathogen has difficulty advancing more than $5 \mathrm{~cm}$ internally beyond the external canker margin. This information should be used by growers as a best practice to safely remove cankers from their fig orchards. This investigation represents a contribution to our understanding of this destructive emerging pathogen in California fig orchards, and future research should aim at developing efficient control strategies.

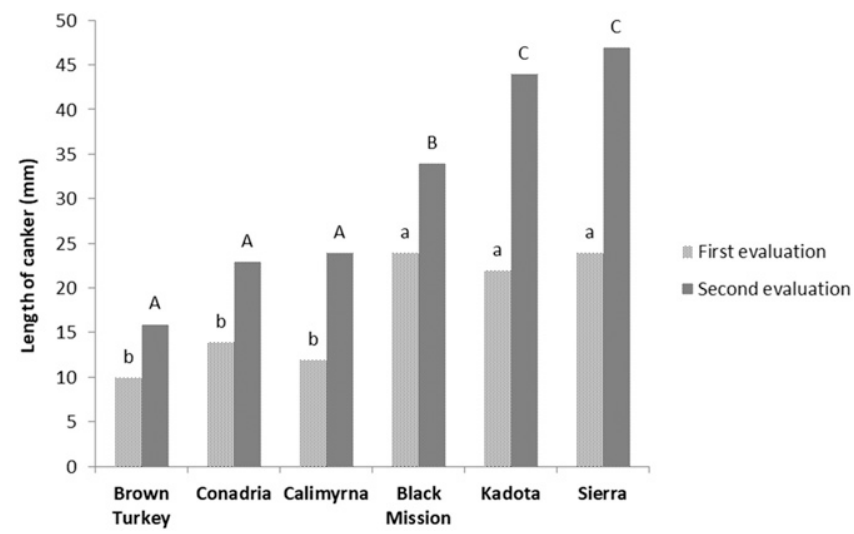

Fig. 5. Cultivar susceptibility (as indicated by lesion length) to limb dieback disease caused by Neoscytalidium dimidiatum. Different letters above columns indicate significantly different treatments $(P<0.05)$. Letters refer to specific (first and second) disease evaluation.

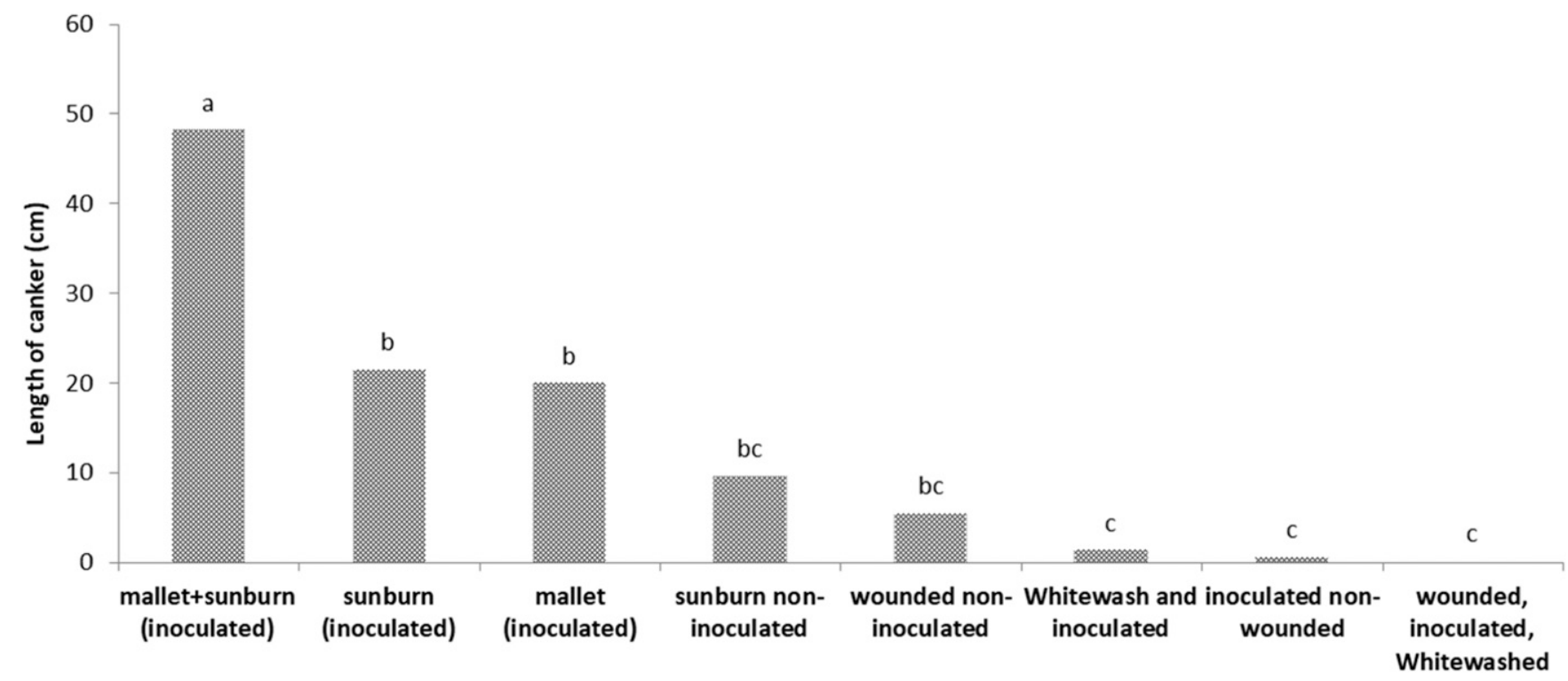

Fig. 4. Effects of different stress factors on lesion length after inoculation of fig shoots with Neoscytalidium dimidiatum. Different letters above columns indicate significantly different treatments $(P<0.05)$ 


\section{Acknowledgments}

We thank D. Felts, H. Reyes, M. Krugner, J. Windh, and R. Puckett for helping with the surveys and with experiments in the lab and field.

\section{Literature Cited}

Aiello, D., Gusella, G., Fiorenza, A., Guarnaccia, V., and Polizzi, G. 2020. Identification of Neofusicoccum parvum causing canker and twig blight on Ficus carica in Italy. Phytopathol. Mediterr. 59:147-153.

Al-Bedak, O. A., Mohamed, R. A., and Seddek, N. H. 2018. First detection of Neoscytalidium dimidiatum associated with canker disease in Egyptian Ficus trees. For. Pathol. 48:e12411.

Analytical Software. 2013. Statistix 10. User's Manual. Analytical Software, Tallahassee, FL.

Banihashemi, Z., and Javadi, A. R. 2009. Further investigations on the biology of Phomopsis cinerascens, the cause of fig canker in Iran. Phytopathol. Mediterr. 48:454-460.

Calavan, E. C., and Wallace, J. M. 1954. Hendersonula toruloidea Nattrass on Citrus in California. Phytopathology 44:635-639.

Çeliker, N. M., and Michailides, T. J. 2012. First report of Lasiodiplodia theobromae causing canker and shoot blight of fig in Turkey. New Dis. Rep. 25:12.

Chen, S. F., Morgan, D. P., Hasey, J. K., Anderson, K., and Michailides, T. J. 2014a. Phylogeny, morphology, distribution, and pathogenicity of Botryosphaeriaceae and Diaporthaceae from English walnut in California. Plant Dis. 98:636-652.

Chen, S. F., Morgan, D. P., and Michailides, T. J. 2014b. Botryosphaeriaceae and Diaporthaceae associated with panicle and shoot blight of pistachio in California, USA. Fungal Divers. 67:157-179.

Crisosto, C. H., Ferguson, L., Preece, J. E., Michailides, T. J., Haug, M. T., López Corrales, M., and Crisosto, G. M. 2017. Developing the California fresh fig industry. Acta Hortic.: 285-292.

Crous, P. W., Slippers, B., Wingfield, M. J., Rheeder, J., Marasas, W. F. O., Philips, A. J. L., Alves, A., Burgess, T., Barber, P., and Groenewald, J. Z. 2006. Phylogenetic lineages in the Botryosphaeriaceae. Stud. Mycol. 55:235-253.

Davison, A. D. 1972. Factors affecting development of madrone canker. Plant Dis. Rep. 56:50-52.

Derviş, S., Türkölmez, Ş., Çiftçi, O., Ulubaş Serçe, Ç., and Dikilitas, M. 2019. First report of Neoscytalidium dimidiatum causing black canker and root rot of walnut in Turkey. Plant Dis. 103:2129.

Doster, M. A., Michailides, T. J., and Morgan, D. P. 1996. Aspergillus species and mycotoxins in figs from California orchards. Plant Dis. 80:484-489.

El-Atta, H. A., and Aref, I. M. 2013. Pathogenic mortality of Ficus spp. IJPAES 3: 204-210.

Elshafie, A. E., and Ba-Omar, T. 2002. First report of Albizia lebbeck dieback caused by Scytalidium dimidiatum in Oman. Mycopathologia 154:37-40.

English, H., Davis, J. R., and De Vay, J. E. 1975. Relationship of Botryosphaeria dothidea and Hendersonula toruloidea to a canker disease of almond. Phytopathology 65:114-122.

English, H. W. 1951. Phomopsis canker: a progress report. Pages 45-48 in: Proceedings of the fifth Annual Research Conference of the California Fig Institute, Fresno, CA.

English, H. W. 1952. Pruning and spraying experiments for Phomopsis canker. Pages 16-19 in: Proceedings of the sixth Annual Research Conference of the California Fig Institute. Fresno, CA.

Farr, D. F., Elliott, M., Rossman, A. Y., and Edmonds, R. L. 2005. Fusicoccum arbuti sp. nov, causing cankers on Pacific madrone in western North America with notes on Fusicoccum dimidiatum, the correct name for Scytalidium dimidiatum and Nattrassia mangiferae. Mycologia 97:730-741.

Ferguson, L., Michailides, T. J., and Shorey, H. H. 1990. The California fig industry. Hortic. Rev. (Am. Soc. Hortic. Sci.) 12:409-490.

Fullerton, R. A., Sutherland, P. A., Rebstock, R. S., Hieu, N. T., Thu, N. N. A., Linh, D. T., Thanh, N. T. K., and Van Hoa, N. 2018. The life cycle of dragon fruit canker caused by Neoscytalidium dimidiatum and implications for control. Manag Pest Dis. 158. https://dfnet.fftc.org.tw/Page/ArticleDetail.aspx? ArticleID $=9$ LeTiREiqsA $\% 3 \mathrm{D} \& \mathrm{PI}=\mathrm{ZeDMUJUrfPk} \% 3 \mathrm{D} \& \mathrm{Co}=\mathrm{ztBzV} \% 2 \mathrm{~F} 10 \mathrm{sco} \%$ $3 \mathrm{D} \& \mathrm{Ca}=\mathrm{ztBzV} \% 2 \mathrm{~F} 10 \mathrm{sco} \% 3 \mathrm{D} \& \mathrm{Ws}=\mathrm{ztBzV} \% 2 \mathrm{~F} 10 \mathrm{sco} \% 3 \mathrm{D} \&$ Keyword=ztBzV$\%$ $2 \mathrm{~F} 10 \mathrm{sco} \% 3 \mathrm{D}$

Giha, O. H. 1975. Hendersonula toruloidea associated with serious wilt disease of shade trees in the Sudan. Plant Dis. Rep. 59:899-902.

Hampson, M. C. 1981. Phomopsis canker on weeping fig in Newfoundland. Can. Plant Dis. Surv. 61:3-5.

Hansen, H. N. 1949. Phomopsis canker of fig. Calif. Agric.: 13-14.

Hassan, W. A., Haleem, R. A., and Hassan, P. H. 2011. Effect of heat-stress predisposition on the development of sooty canker caused by Neoscytalidium dimidiatum (Penz.) Crous and Slippers. Acta Agrobot. 64: 207-212.

Hassan, W. A., Pasha, A. A., and Mohammad, M. B. 2009. Sooty canker on some thin bark trees caused by Nattrassia mangiferae. Egypt. J. Agric. Res. 87: 443-456.
Inderbitzin, P., Bostock, R. M., Trouillas, F. P., and Michailides, T. J. 2010. A six locus phylogeny reveals high species diversity in Botryosphaeriaceae from California almond. Mycologia 102:1350-1368.

Javadi, A. R., and Banihashemi, Z. 2005. Biology and pathogenicity of Phomopsis cinerascens, the causal agent of fig canker in Fars Province of Iran. In III International Symposium on Fig. 16-20 May 2005, Vilamoura, Algarve, Portugal. 798: 219-222.

Lima, M. L. P., Uesugi, C. H., and Santos, G. R. 2005. First record of dieback of Ficus benjamina caused by Phomopsis cinerescens in the States of Tocantins and Minas Gerais. Fitopatol. Bras. 30:91.

López-Moral, A., Raya-Ortega, M. C., Agustí-Brisach, C., Roca, L. F., Lovera, M., Luque, F., et al. 2017. Morphological, pathogenic, and molecular characterization of Colletotrichum acutatum isolates causing almond anthracnose in Spain. Plant Dis. 101:2034-2045.

Marques, M. W., Lima, N. B., de Morais, M. A., Michereff, S. J., Phillips, A. J., and Câmara, M. P. 2013. Botryosphaeria, Neofusicoccum, Neoscytalidium and Pseudofusicoccum species associated with mango in Brazil. Fungal Divers. 61: 195-208.

Mayorquin, J. S., Eskalen, A., Downer, A. J., Hodel, D. R., and Liu, A. 2012. First report of multiple species of the Botryosphaeriaceae causing bot canker disease of Indian laurel-lea fig in California. Plant Dis. 96:459.

Mayorquin, J. S., Wang, D. H., Twizeyimana, M., and Eskalen, A. 2016. Identification, distribution, and pathogenicity of Diatrypaceae and Botryosphaeriaceae associated with citrus branch canker in the Southern California desert. Plant Dis. 100:2402-2413.

Michailides, T. J. 2003. Diseases of figs. Pages 253-273 in: Diseases of Tropical Fruit Crops. R. C. Ploetz, ed. CABI Publishing, Cambridge, MA.

Michailides, T. J., and Morgan, D. P. 1998. Spread of endosepsis in Calimyrna fig orchards. Phytopathology 88:637-647.

Mirzaee, M. R., Mohammadi, M., and Rahimian, H. 2002. Nattrassia mangiferae, the cause of die-back and trunk cankers of Ficus religiosa and branch wilt of Psidium guajava in Iran. J. Phytopathol. 150:244-247.

Mohali, S. R., Castro Medina, F., Úrbez-Torres, J. R., and Gubler, W. D. 2017 First report of Lasiodiplodia theobromae and L. venezuelensis associated with blue stain on Ficus insipida wood from the Natural Forest of Venezuela. For. Pathol. 47:e12355.

Moral, J., Morgan, D., Trapero, A., and Michailides, T. J. 2019. Ecology and epidemiology of diseases of nut crops and olives caused by Botryosphaeriaceae fungi in California and Spain. Plant Dis. 103:1809-1827.

Nattrass, R. M. 1933. A new species of Hendersonula (H. toruloidea) on deciduous trees in Egypt. Br. Mycol. Soc. Trans. 18:189-198.

Nouri, M. T., Lawrence, D. P., Yaghmour, M. A., Michailides, T. J., and Trouillas, F. P. 2018. Neoscytalidium dimidiatum causing canker, shoot blight and fruit rot of almond in California. Plant Dis. 102:1638-1647.

Obenauf, G., Gerdts, M., Leavitt, G., and Crane, J. 1978. Commercial dried fruit production in California. In: University of California Agr. Ext. Leaflet 21051: 25.

Oren, Y., Sadowsky, A., Gefen, D., Solel, Z., and Kimchy, M. 2001. Scytalidium wilt of citrus. Eur. J. Plant Pathol. 107:467-470.

Paxton, J. D., Wilson, E. E., and Davis, J. R. 1964. Branch wilt disease of fig caused by Hendersonula toruloidea. Plant Dis. Rep. 48:142.

Polizzi, G., Aiello, D., Vitale, A., Giuffrida, F., Groenewald, J. Z., and Crous, P. W. 2009. First report of shoot blight, canker, and gummosis caused by Neoscytalidium dimidiatum on citrus in Italy. Plant Dis. 93:1215.

Ray, J. D., Burgess, T., and Lanoiselet, V. M. 2010. First record of Neoscytalidium dimidiatum and $N$. novaehollandiae on Mangifera indica and $N$. dimidiatum on Ficus carica in Australia. Australas. Plant Dis. Notes 5:48-50.

Rehab, M. A., Rashed, M. F., Ammar, M. I., and El-Morsy, S. A. 2014. Dieback and sooty canker of Ficus trees in Egypt and its control. PJBS 17:364-371.

Rolshausen, P. E., Akgül, D. S., Perez, R., Eskalen, A., and Gispert, C. 2013. First report of wood canker caused by Neoscytalidium dimidiatum on grapevine in California. Plant Dis. 97:1511.

Sadowsky, A., Solel, Z., and Sztejnberg, A. 2007. Effect of heat-stress predisposition on the development of Scytalidium wilt of 'Star Ruby' grapefruit, caused by Scytalidium lignicola. Eur. J. Plant Pathol. 117: 123-127.

Schoeneweiss, D. F. 1975. Predisposition, stress, and plant disease. Annu. Rev. Phytopathol. 13:193-211.

Sutton, B. C., and Dyko, B. J. 1989. Revision of Hendersonula. Mycol. Res. 93: 466-488.

Türkölmez, Ş., Derviş, S., Çiftçi, O., Serçe, Ç. U., and Dikilitas, M. 2019. New disease caused by Neoscytalidium dimidiatum devastates tomatoes (Solanum lycopersicum) in Turkey. Crop Prot. 118:21-30.

Warner, R. M. 1952. Pages 24-25 in: Some observations on branch wilt in figs. Proceedings Sixth Annual Res. Confer. California Fig Institute, Madera, CA.

Wilson, E. E. 1949. The pycnidial stage of the walnut branch wilt fungus, Exosporina fawcetti. Phytopathology 39:340-346. 